\title{
TPL-2/COT AND COX-2 IN BREAST CANCER
}

\author{
Zuzana Krcova $^{\mathrm{a} *}$, Jiri Ehrmann ${ }^{\mathrm{a}, \mathrm{c}}$, Veronika Krejci ${ }^{\mathrm{a}}$, Aris Eliopoulos ${ }^{\mathrm{b}}$, Zdenek Kolar $^{\mathrm{a}}$
}

\author{
a Laboratory of Molecular Pathology, Department of Pathology, Faculty of Medicine and Dentistry, Palacky University and \\ University Hospital, 77515 Olomouc, Czech Republic \\ ${ }^{b}$ Molecular and Cellular Biology Laboratory, Basic Science Division, University of Crete Medical School, Heraklion, Crete, \\ Greece \\ c Department of Histology and Embryology, Faculty of Medicine and Dentistry, Palacky University, 775 15 Olomouc, Czech \\ Republic \\ e-mail:krcova.zuzana@seznam.cz
}

Received: February 10, 2008; Accepted: March 5, 2008

Key words: Tpl2/Cot/COX-2/Breast cancer

Background: Breast cancer is the most common cancer in women worldwide and although mortality (129 000/year) stagnates, incidence (370 000/year) is increasing. In addition to histological type, grade, stage, hormonal and c-erbB2 status there is therefore a strong need for new and reliable prognostic and predictive factors.

Methods and results: This minireview focuses on two potential prognostic and predictive candidates Tp12/Cot and COX-2 and summarise information about them.

Conclusion: Tumor progression locus 2 (Tp12/Cot) is a serine/threonine protein kinase belonging to the family of MAP3 kinases. Activated Tp12/Cot leads to induction of ERK1/2, JNK, NF-kB and p38MAPK pathways. The first study on Tp12/Cot mRNA in breast cancer showed its increase in $40 \%$ of cases of breast cancer but no available data exist on protein expression. Cyclo-oxygenase $2(\mathrm{COX}-2)$ is inducible by growth and inflammatory factors and contributes to the development of various tumours. Expression of COX-2 in breast cancer varied from 5-100 \% in reviewed papers with significantly higher values in poorly differentiated tumours. Tp12/Cot and COX-2 have their importance in different intracellular pathways and some of these are involved in cancer development. Briefly, the results from recent studies suggest that Tpl2/Cot and COX-2 could be prognostic factors in breast cancer.

\section{INTRODUCTION}

Breast cancer is the most common cancer type in women worldwide. The incidence of this disease was approximately 370 000/year in Europe from 2000 to 2005. This includes $27.4 \%$ of all cancer types. With 129000 deaths/year (17.4\%) it is the most common cause of cancer death in women ${ }^{1}$. The incidence and mortality in Czech Republic is similar to the rest of Europe: breast cancer is the cause of every fourth death and although the incidence is increasing, mortality stagnates and in some countries decrease was registered ${ }^{2,3}$. According to WHO classification, the largest group of breast carcinoma is ductal carcinoma ( $80 \%$ ), followed by $12 \%$ of lobular carcinoma, $8 \%$ covers rare tumours such as tubular carcinoma, Paget's carcinoma, sarcoma or lymphoma ${ }^{4}$. Recently a new classification has been proposed according to the molecular expressing profile and application of DNA chip arrays. Breast carcinomas are divided into the four subtypes: luminal subtype, normal basal-like subtype, HER2 positive subtype and basal-like breast cancer $^{5}$ with varying sensitivity to tamoxifen, etoposide and 5-flourouracil in particular groups. It is clear that assessment of histological type is only one part of the process of establishing a diagnosis, prognosis and prediction of these tumours and as many reviews make clear $^{5-7}$, in addition to histological type, grade, stage, hormonal and c-erbB2 status, new specific markers which could aid in the prognosis and prediction of breast cancer are still needed.
Recently, the inflammatory molecules have emerged as important in the development of cancer - inflammatory mediators are in large measure responsible for the events leading to the formation, growth and metastasis of tumours. This has been widely reviewed by Aggarwal et al. ${ }^{8}$. This minireview is focused on two potential candidates, Tpl2/Cot and COX-2 which seems to play a particular role during progression and metastasis of breast cancer ${ }^{9}$.

\section{TPL-2}

Tumor progression locus 2 or Tp12/Cot is a serine/threonine protein kinase belonging to the family of mitogen-activated protein 3 kinases. It was first identified in T-cell lymphoma induced by MoMuL (Moloney murine leukaemia) virus and in breast carcinoma induced by MMT (mouse mammary tumour) virus ${ }^{10}$. In non-stimulated cells, Tpl2/Cot is inactive and exists in a complex with p105 regulation subunit also known as NF-kB1 (ref. ${ }^{10,11}$ ), which is a negative regulator of Tp12/Cot activity ${ }^{12}$. Phosphorylation of p105 on its C-terminal region and $\mathrm{Tp} 12 /$ Cot phosphorylation at Thr290 leads to its release from p105 and subsequently, a further phosphorylation of Tp12/Cot on Ser62 via IL-1 stimulated protein kinase leads to its full activation ${ }^{13-16}$.

Tp12/Cot can be activated by bacterial lipopolysachide (LPS), an endotoxin derived from the wall of Gram-negative bacteria ${ }^{17}$. For instance, Tp12/Cot endogenous activity increases 10 -fold in macrophages after LPS stimulation ${ }^{18}$. Activation of Tp12/Cot via LPS is mediated by transmem- 


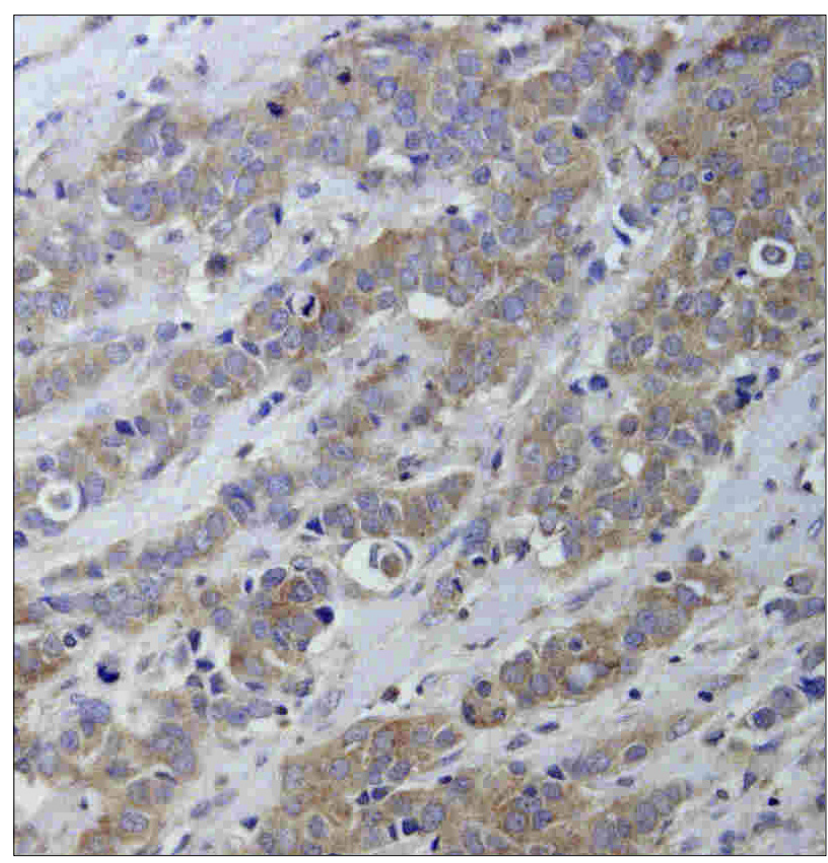

Fig. 1. Moderate to high cytoplasmic expression of Tp12/Cot in invasive ductal breast carcinoma. Magnification x 200. (Anti -TPL2 antibody; rabbit-polyclonal; dilution 1 : 50; Santa Cruz)

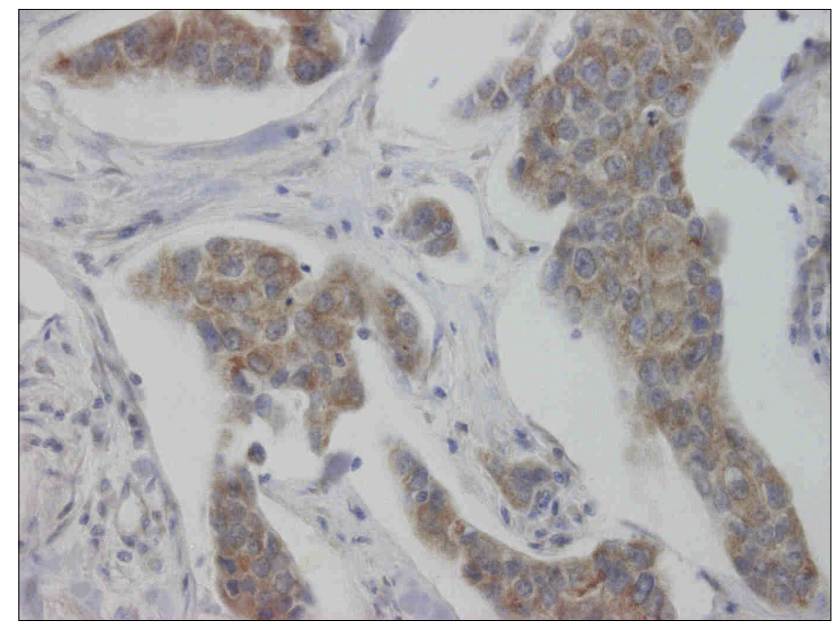

Fig. 3. Moderate to high cytoplasmic expression of COX-2 in invasive ductal breast carcinoma. Magnification x 200. (Anti-COX-2 antibody; rabbit-polyclonal; dilution 1:50; Santa Cruz)

brane receptor TLR4 (Toll-like receptor) ${ }^{19}$. Interestingly, activation of Tp12/Cot is achieved through similar mechanisms by paclitaxe ${ }^{18}$. Kelly et al. have found a relation between activation of TLR4 signalling pathway and chemoresistance to paclitaxel therapy in ovarian cancer. Hence if this correlation is found in breast cancer, then changes in expression of TLR4 or increased activity of Tp12/Cot could predict inefficiency of taxane-based treatment ${ }^{20,21}$.

Tp12/Cot is part of several intracellular signalling pathways and for some of them its role is pivotal. Over-

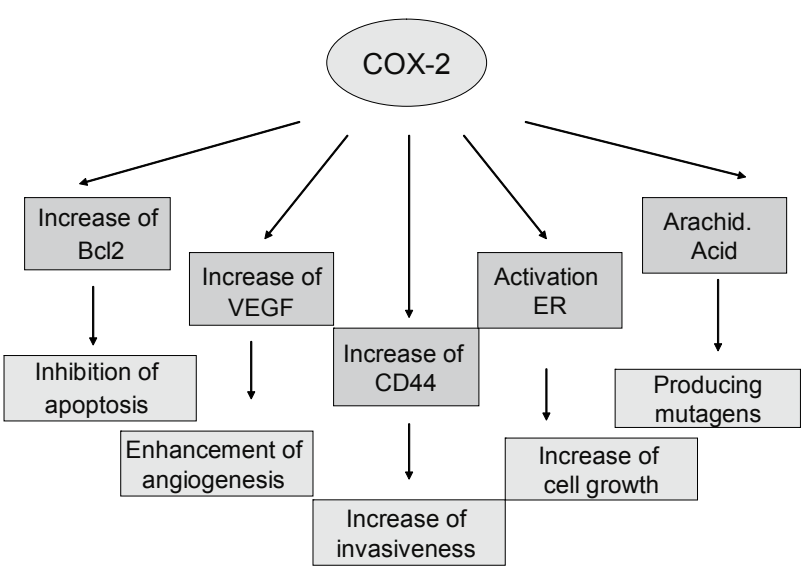

Fig. 2. Contribution of COX-2 to the carcinogenesis.

expression of Tp12/Cot leads to activation of ERK1/2, JNK, NF- $k$ B and p38MAPK pathways ${ }^{17,22}$. ERK activation via Tp12/Cot is based on TRAF6 and TRAF2 association with CD40 (member of the TNF superfamily) and subsequent Tp12/Cot binding with TAK1/TAB complex, which results in induction of $\mathrm{NF}-\mathrm{kB}^{23-26}$. Another role of Tp12/Cot is negative regulation of Th1-type adaptive immunity by inhibiting IL-12 production ${ }^{27}$ and induction of RANKL in response to synthetic lipid A in osteoblasts ${ }^{28}$. Tp12/Cot also affects the subcellular distribution of the COX-2 message and promotes stabilization of this protein in cells ${ }^{29}$.

Negative regulators of Tp12/Cot activated ERK1/2 pathway are arrestin-2 and GRK5 (G protein-coupled receptor kinase 5). Arrestin-2 binds directly to the $\mathrm{COOH}$ terminal region of p105 and this blocks phosphorylation and release Tp12/Cot from p105. GRK5 also directly interacts with p105 (ref. ${ }^{30}$ ).

The first studies on experimental inhibition of Tp12/Cot demonstrated the importance of this molecule. Quinolin-3-carbonitril was identified as a potent and selective Tp12/Cot inhibitor in rheumatoid arthritis ${ }^{31}$. 15Deoxy- $\Delta 12$, 14-prostaglandin $\mathrm{J} 2$, a potent natural ligand of PPAR- $\gamma$, also completely suppressed the activation of Tp12/Cot activated by LPS or Paclitaxel ${ }^{18}$.

Activation of Tp12/Cot has been shown both in various inflammatory processes such as pancreatitis and rheumatoid arthritis and in tumours such as T-cell neoplasias, breast cancer cell lines, etc. ${ }^{10-36}$.

The first study focused on Tpl2/Cot mRNA in breast cancer tissues showed its overexpression in $40 \%$ of cases, and significant correlation to Tp12/Cot gene amplification $^{32}$. Moreover, positive significant association with TNM stage I was identified in the same study, indicating that this molecular alteration may be an early event in the development of the disease. It was also suggested, that overexpression of the progesterone receptor correlates 
Tpl 2/Cot expression in relation to $P R$ and c-erbB-2.

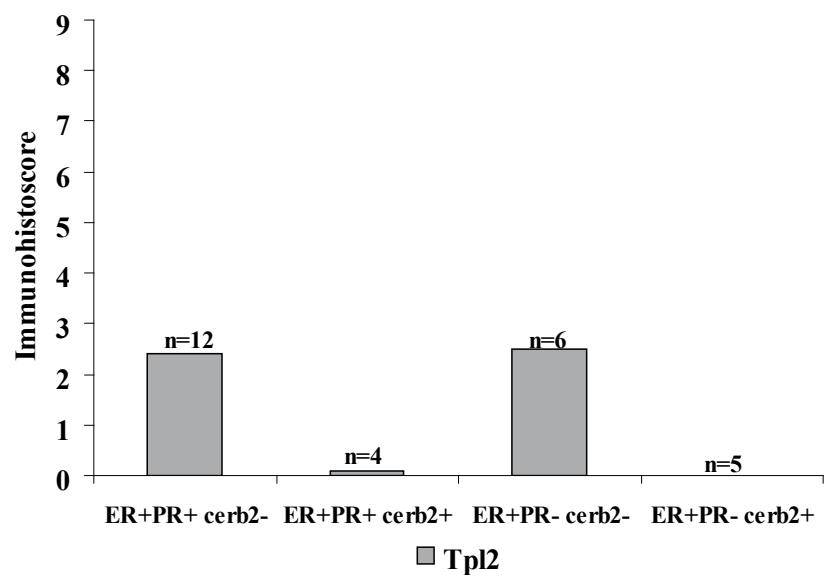

Graph 1. Significant increase of Tpl2/Cot expression in c-erbB-2 negative carcinomas ( $p \leq 0,001)$.

STAT3 expression in relation to $P R$ and c-erbB-2.

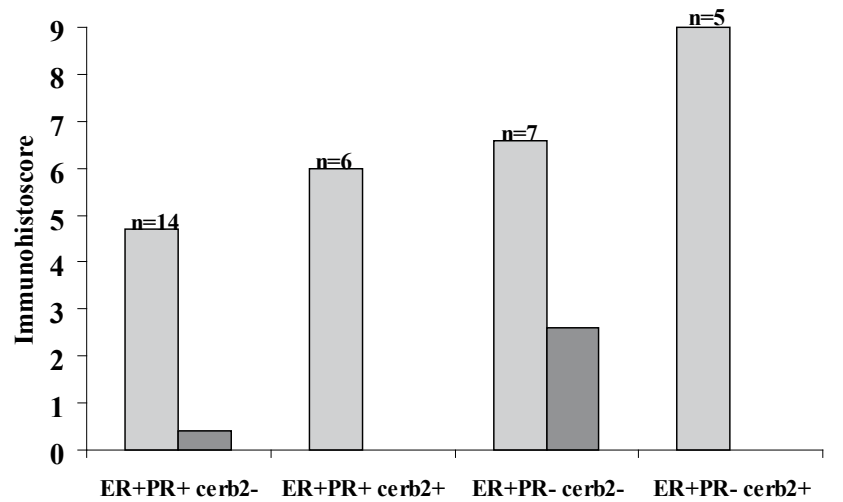

$\square$ STAT3cyt $\square$ STAT3ncl

Graph 2. Significant increase of STAT3 nuclear expression in c-erbB-2 negative carcinomas $(\mathrm{p} \leq$ $0,014)$.

with overexpression of $\mathrm{Tp} 12 / \operatorname{Cot}^{32}$, but larger studies, to elucidate its relation to oestrogen and progesterone receptors, Her2/neu and histological features do not exist to date. Our preliminary results from immunohistochemical study on tissue microarrays (TMA) of 32 cases of invasive ductal carcinomas showed significant increase in Tp12/Cot expression in c-erbB-2 negative carcinomas ${ }^{33}$ ( $\mathrm{p} \leq 0,001$, Fig. 1, Graph 1). Interestingly, this increase also correlated with enhanced nuclear expression of STAT3, another molecule involved in immunity and inflammation, in the same group of tumours ( $\mathrm{p} \leq 0,014$, Graph 2). The potential predictive value of increased Tp12/Cot and STAT3 expression is supported by the finding that inhibition of STAT3 increases response to the proapoptotic effects of doxorubicin in breast cancer cells (MDA-MB-231)(ref. $\left.{ }^{34}\right)$. Moreover, another STAT family member, STAT $5 \mathrm{~b}$, showed a relation to the induction of differentiation in breast cancer cells transfected with progesterone DNA ${ }^{35}$. For this reason, in poor prognosis patients without expression of progesterone receptor, STAT5b may also play prognostic role - its absence may contribute to poor prognosis. Taken together, despite the small size of this studied series, these results indicate that increased Tp12/Cot and STAT3 expression in c-erB-2 negative breast cancer tumours could by another important prognostic and predictive factor.

\section{COX-2}

Cyclo-oxygenase 2 (also prostaglandin endoperoxide synthase 2), is the most extensively studied proteins in human cancer: COX-2 is inducible by growth factors and inflammation stimuli and as has been described in several reviews ${ }^{37-40} \mathrm{COX}-2$ contributes to the development of various types of tumour ${ }^{41-43}$

In breast cancer COX-2 play role in these processes ${ }^{37-40}$ (Fig. 2):

- inhibition of apoptosis by induction of PGE2, which leads to increased expression of antiapoptotic protein BCL-2 and decreased expression of proapoptotic protein BAX and to weakening of nitric oxide (NO) signals

- enhanced angiogenesis due to increased PGE 2 level, followed by increased VEGF, endothelin-1 and PDGF production

- increased invasiveness via overexpression of CD44

- increased cell growth via oestrogen receptor activation

- producing mutagens by metabolism of arachidonic acid

Howe and Dannenberg found that elevated levels of COX-2 protein correlate with tumour size, high proliferation rate, axillary node metastases, histology, human epidermal growth factor receptor 2 (HER-2) gene amplification and decreased disease-free survival in breast can$\operatorname{cer}^{40}$. Association of high COX-2 expression with reduced disease-free survival and also with disease-related survival was also found in oestrogen receptor (ER) negative breast cancers ${ }^{44}$. Expression of COX-2 in cancer cells varied from $5 \%$ to $100 \%$ in reviewed papers with an average score of $40 \% 38,40,44$. COX-2 expression was found both in invasive and in in situ breast cancer ${ }^{43}$ and, in poorly differentiated carcinomas, the intensity of expression was significantly higher ${ }^{45}$. Adjacent, non-neoplasmic tissues were negative for COX-2 staining ${ }^{45}$. As in these studies, our results on tissue microarrays (TMA) of 32 cases of invasive ductal carcinomas show diffuse strong cytoplasmatic, granular expression of COX-2 in all studied tumors (Fig. 3)(ref. ${ }^{33}$ ).

The role of COX-2 gene polymorphism in breast cancer development is also a matter of current discussion. Women homozygous for $T$ allele at 5275 had a $20 \%$ lower risk of breast cancer than those with homozygous for $C$ allele ${ }^{46}$.

COX-2 is also a target for therapy by selective (celecoxib) or non-selective non-steroid anti-inflammatory drugs (aspirin, indomethacin) in several diseases and their protective contribution against the development of 
various tumour types has been shown in animal mouse and rodent models ${ }^{38}$. Studies on rodent breast cancer have shown a significant decrease in the incidence, multiplicity and volume of tumour after selective NSAIDs treatment $^{38,40}$.

The correlation between Her2/neu and COX-2 is also interesting; in celecoxib-treated mice with positive Her2/neu the progression of breast tumours was significantly lower. The blood levels of celecoxib in mice were within the range reported to inhibit inflammation ${ }^{47}$. When COX-2 knockout mice with the same type of breast tumours were investigated, similar results such as decrease in PGE2 production, decreased multiplicity of tumours, decreased angiogenesis and smaller size of lesions, was observed $^{48}$. Howe and Dannenberg ${ }^{38-40}$ summarized a large number of studies and suggested that COX-2 inhibitors could be a good target not only for treatment but also for the prevention of breast cancer.

\section{ACKNOWLEDGEMENTS}

Supported by grants VZ MSM 6198959216 and 6FP LSHC-CT-2006-037344 and IGA UP 91110191.

\section{REFERENCES}

1. Boyle P, Ferlay J. Cancer incidence and mortality in Europe, 2004. Ann Oncol. 2005; 16:481-8.

2. Institute of Health Information and Statistics of the Czech Republic. Czech health statistics yearbook 2005. IHIS CR. Prague; 2006.

3. Institute of Health Information and Statistics of the Czech Republic, National Oncologic Registry of the Czech Republic. Cancer incidence 2004 in the Czech Republic. IHIS CR, NOR CR. Prague; 2007.

4. Tavassoli FA, Devilee P. World health organization classification of tumors. Pathology and genetics of tumours of the breast and female genital organs. IARC Press: Lyon; 2003.

5. Brenton JD, Carey LA, Ahmed AA, Caldas C. Molecular classification and molecular forecasting of breast cancer: ready for clinical application? J Clin Oncol. 2005; 23:7350-60.

6. Potti A, Dressman HK, Bild A, Riedel RF, Chan G, Sayer R et al. Genomic signatures to guide the use of chemotherapeutics. Nat Med. 2006; 12:1294-300.

7. Jansen MP, Foekens JA, van Staveren IL, Dirkzwager-Kiel MM, Ritstier K, Look MP et al. Molecular classification of tamoxifenresistant breast carcinomas by gene expression profiling. J Clin Oncol. 2005; 23:732-40.

8. Aggarwal BB, Shishodia S, Sandur SK, Pandey MK, Sethi G. Inflammation and cancer: how hot is the link? Biochem Pharmacol. 2006; 72:1605-21.

9. Larkins TL, Nowell M, Singh S, Sanford GL. Inhibition of cyclooxygenase-2 decreases breast cancer cell motility, invasion and matrix metalloproteinase expression. BMC Cancer. 2006; 6:181. Available from: http://www.biomedcentral.com/1471-2407/6/181

10. Patriotis C, Makris A, Bear SE, Tsichlis PN. Tumor progression locus 2 (Tpl-2) encodes a protein kinase involved in the progression of rodent T-cell lymphomas and in T-cell activation. Proc Natl Acad Sci U S A. 1993; 90:2251-5.

11. Lang V, Symons A, Watton SJ, Janzen J, Soneji Y, Beinke $\mathrm{S}$ et al. ABIN-2 forms a ternary complex with TPL-2 and NF-kappa B1 p105 and is essential for TPL-2 protein stability. Mol Cell Biol. 2004; 24:5235-48.

12. Beinke S, Deka J, Lang V, Belich MP, Walker PA, Howell S et al.
NF-kappaB1 p105 negatively regulates TPL-2 MEK kinase activity. Mol Cell Biol. 2003; 23:4739-52.

13. Luciano BS, Hsu S, Channavajhala PL, Lin LL, Cuozzo JW. Phosphorylation of threonine 290 in the activation loop of Tp12/ Cot is necessary but not sufficient for kinase activity. J Biol Chem. 2004; 279:52117-23.

14. Stafford MJ, Morrice NA, Peggie MW, Cohen P. Interleukin-1 stimulated activation of the COT catalytic subunit through the phosphorylation of Thr290 and Ser62. FEBS Lett. 2006; 580:4010-4.

15. Cho J, Tsichlis PN. Phosphorylation at Thr-290 regulates Tpl2 binding to NF-kappaB1/p105 and Tpl2 activation and degradation by lipopolysaccharide. Proc Natl Acad Sci U S A. 2005; 102:2350-5.

16. Cho J, Melnick M, Solidakis GP, Tsichlis PN. Tpl2 (tumor progression locus 2) phosphorylation at Thr290 is induced by lipopolysaccharide via an Ikappa-B Kinase-beta-dependent pathway and is required for Tpl2 activation by external signals. J Biol Chem. 2005; 280:20442-8.

17. Dumitru CD, Ceci JD, Tsatsanis C, Kontoyiannis D, Stamatakis $\mathrm{K}$, Lin JH et al. TNF-alpha induction by LPS is regulated posttranscriptionally via a Tp12/ERK-dependent pathway. Cell. 2000; 103:1071-83.

18. Caivano M, Rodriguez C, Cohen P, Alemany S. 15-DeoxyDelta12,14- prostaglandin J2 regulates endogenous Cot MAPK kinase kinase 1 activity induced by lipopolysaccharide. J Biol Chem. 2003; 278:52124-30.

19. Banerjee A, Gugasyan R, McMahon M, Gerondakis S. Diverse Tolllike receptors utilize Tpl2 to activate extracellular signal-regulated kinase (ERK) in hemopoietic cells. Proc Natl Acad Sci U S A. 2006; 103:3274-9.

20. Azambuja E, Durbecq V, Rosa D, Colozza M, Larsimont D, Piccart-Gebhart M et al.. HER-2 overexpression/amplification and its interaction with taxane-based therapy in breast cancer. Ann Oncol. 2007. Available from: http://annonc.oxfordjournals.org/ cgi/content/full/mdm352v1

21. Kelly MG, Alvero AB, Chen R, Silasi DA, Abrahams VM, Chan $\mathrm{S}$ et al. TLR-4 signaling promotes tumor growth and paclitaxel chemoresistance in ovarian cancer. Cancer Res. 2006; 66:385968 .

22. Das S, Cho J, Lambertz I, Kelliher MA, Eliopoulos AG, Du K et al. Tp12/cot signals activate ERK, JNK, and NF-kappaB in a cell-type and stimulus-specific manner. J Biol Chem. 2005; 280:23748-57.

23. Eliopoulos AG, Wang CC, Dumitru CD, Tsichlis PN. Tpl2 transduces CD40 and TNF signals that activate ERK and regulates IgE induction by CD40. EMBO J. 2003; 22:3855-64.

24. Chan H, Reed JC. TRAF-dependent association of protein kinase Tpl2/COT1 (MAP3K8) with CD40. Biochem Biophys Res Commun. 2005; 328:198-205.

25. Hill SC, Youde SJ, Man S, Teale GR, Baxendale AJ, Hislop A et al. Activation of CD40 in cervical carcinoma cells facilitates CTL responses and augments chemotherapy-induced apoptosis. J Immunol. 2005; 174:41-50.

26. Tsatsanis Ch, Patriotis C, Bear SE, Tsichlis PN. The Tpl-2 protooncoprotein activates the nuclear factor of activated $\mathrm{T}$ cells and interleukin 2 expressions in T cell lines. Immunology. 1998; 95:3827-32.

27. Sugimoto K, Ohata M, Miyoshi J, Ishizaki H, Tsuboi N, Masuda A et al. A serine/threonine kinase, Cot/Tpl2, modulates bacterial DNA-induced IL-12 production and Th cell differentiation. J Clin Invest. 2004; 114:857-66.

28. Kikuchi T, Yoshikai Y, Miyoshi J, Katsuki M, Musikacharoen T, Mitani A et al. Cot/Tpl2 is essential for RANKL induction by lipid A in osteoblasts. J Dent Res. 2003; 82:546-50.

29. Eliopoulos AG, Dumitru CD, Wang CC, Cho J, Tsichlis PN. Induction of COX-2 by LPS in macrophages is regulated by Tpl2dependent CREB activation signals. EMBO J. 2002; 21:4831-40.

30. Parameswaran N, Pao CS, Leonhard KS, Kang DS, Kratz M, Ley $\mathrm{SC}$ et al. Arrestin-2 and G protein-coupled receptor kinase 5 interact with NFkappaB1 p105 and negatively regulate lipopolysaccharide-stimulated ERK1/2 activation in macrophages. J Biol Chem. 2006; 281:34159-70.

31. Hu Y, Green N, Gavrin LK, Janz K, Kaila N, Li HQ et al. Inhibition of Tp12 kinase and TNFalpha production with quinoline-3-carboni- 
triles for the treatment of rheumatoid arthritis. Bioorg Med Chem Lett. 2006; 16:6067-72.

32. Sourvinos G, Tsatsanis C, Spandidos DA. Overexpression of the Tpl-2/Cot oncogene in human breast cancer. Oncogene. 1999; 185:4968-73.

33. Krcova Z, Ehrmann J, Eliopoulos A, Turashvili G, Klein J, Kolar Z et al. Tpl2/Cot as a new prognostic and predictive factor in breast cancer? Virchows Arch. 2007; 451:142-3.

34. Gariboldi MB, Ravizza R, Molteni R, Osella D, Gabano E, Monti E. Inhibition of Stat 3 increases doxorubicin sensitivity in a human metastatic breast cancer cell line. Cancer Lett. 2007; 258:181-8.

35. Lin VC, Jin R, Tan PH, Aw SE, Woon CT, Bay BH. Progesterone induces cellular differentiation in MDA-MB-231 breast cancer cells transfected with progesterone receptor complementary DNA. Am J Pathol. 2003; 162:1781-7.

36. Christoforidou AV, Papadaki HA, Margioris AN, Eliopoulos GD, Tsatsanis C. Expression of the Tpl2/Cot oncogene in human Tcell neoplasias. Mol Cancer. 2004 Dec 3;3(1): 34. Available from: http://www.molecular-cancer.com/content/3/1/34

37. Wendum D, Masliah J, Trugnan G, Flejou JF. Cyclooxygenase2 and its role in colorectal cancer development. Virchows Arch. 2004; 445:327-33.

38. Howe LR, Subbaramaiah K, Brown AM, Dannenberg AJ. Cyclooxygenase-2: a target for the prevention and treatment of breast cancer. Endocr Relat Cancer. 2001; 8:97-114.

39. Dannenberg AJ, Altorki NK, Boyle JO, Dang C, Howe LR, Weksler $\mathrm{BB}$ et al. Cyclo-oxygenase 2: a pharmacological target for the prevention of cancer. Lancet Oncol. 2001; 2:544-51.

40. Howe LR, Dannenberg AJ. COX-2 inhibitors for the prevention of breast cancer. J Mammary Gland Biol Neoplasia. 2003; 8:31-43.

41. Juuti A, Louhimo J, Nordling S, Ristimaki A, Haglund C. Cyclooxygenase-2 expression correlates with poor prognosis in pancreatic cancer. J Clin Pathol. 2006; 59:382-6.
42. Panel V, Boelle PY, Ayala-Sanmartin J, Jouniaux AM, Hamelin $\mathrm{R}$, Masliah $\mathrm{J}$ et al. Cytoplasmic phospholipase A2 expression in human colon adenocarcinoma is correlated with cyclooxygenase-2 expression and contributes to prostaglandin E2 production. Cancer Lett. 2006; 243:255-63.

43. Perrone G, Santini D, Vincenzi B, Zagami M, La Cesa A, Bianchi A et al. COX-2 expression in DCIS: correlation with VEGF, HER2/neu, prognostic molecular markers and clinicopathological features. Histopathology. 2005; 46:561-8.

44. Witton CJ, Hawe SJ, Cooke TG, Bartlett JM. Cyclooxygenase 2 (COX2) expression is associated with poor outcome in ER-negative, but not ER-positive, breast cancer. Histopathology. 2004; 45:47-54.

45. Schmitz KJ, Wohlschlaeger J, Kimmig R, Otterbach F, Bohr J, Lee HS et al. Overexpression of cyclo-oxygenase- 2 is an independent predictor of unfavourable outcome in node-negative breast cancer, but is not associated with protein kinase B (Akt) and mitogen-activated protein kinase (ERK1/2, p38) activation or with Her-2/neu signalling pathways. J Clin Pathol. 2006; 59:685-91.

46. Cox DG, Buring J, Hankinson SE, Hunter DJ. A polymorphism in the 3' untranslated region of the gene encoding prostaglandin endoperoxide synthase 2 is not associated with an increase in breast cancer risk: a nested case-control study. Breast Cancer Res. 2007; 9(1):R3. Available from: http://breast-cancer-research.com/content/9/1/R3

47. Howe LR, Subbaramaiah K, Patel J, Masferrer JL, Deora A, Hudis $\mathrm{C}$ et al. Celecoxib, a selective cyclooxygenase 2 inhibitor, protects against human epidermal growth factor receptor 2 (HER-2)/neuinduced breast cancer. Cancer Res. 2002; 62:5405-7.

48. Howe LR, Chang SH, Tolle KC, Dillon R, Young LJ, Cardiff RD et al. HER2/neuinduced mammary tumorigenesis and angiogenesis are reduced in cyclooxygenase-2 knockout mice. Cancer Res. 2005; 65:10113-9. 